\title{
Políticas públicas de educação superior e desenvolvimento local: as transformações no município de Cachoeira (BA) após a implantação da Universidade Federal do Recôncavo da Bahia
}

\author{
Jorge Antonio Santos Silva \\ Universidade Federal do Recôncavo da Bahia - Cachoeira - Bahia - Brasil \\ Ozana Rebouças Silva \\ Universidade Federal do Recôncavo da Bahia - Cachoeira - Bahia - Brasil
}

\section{Resumo}

Neste trabalho analisa-se a importância da Universidade Federal do Recôncavo da Bahia UFRB no processo de desenvolvimento do município de Cachoeira. A UFRB é fruto de política pública nacional para a expansão do ensino superior no país, e, ao se materializar nos espaços, promoveu transformações, adaptações e requalificações, com resultados às vezes diversos dos planejados pelos formuladores da política, principalmente quando se trata de pequenas e médias cidades. O trabalho se utilizou de pesquisa bibliográfica, documental, eletrônica, visando compreender os reflexos da Universidade no município. Atualmente, as universidades exercem uma grande contribuição para o desenvolvimento socioeconômico, e a UFRB tem grande relevância no atual contexto de dinamização econômica de Cachoeira, de valorização da cultura local e de disseminação do conhecimento. Desta forma, o artigo traz novas possibilidades de reflexão e de entendimento sobre a função e a atuação da UFRB no Recôncavo e sua contribuição ao desenvolvimento local, considerando que é de interesse da sociedade e dos gestores alcançarem efetividade com as ações realizadas, trazendo benefícios sociais para um maior número de pessoas.

Palavras-chave: Desenvolvimento. Políticas Públicas. Universidade. Recôncavo Baiano. 


\title{
Public policies of higher education and local development: the transformations in the Cachoeira/Ba municipality after the Implementation of the Federal University of the Recôncavo of the Bahia
}

\begin{abstract}
This paper analyzes the importance of the Federal University of the Recôncavo of the Bahia - UFRB in the development process of the municipality of Cachoeira, the result of a national public policy for the expansion of higher education in the country, but which materialized in space promoting transformations, adaptations and requalifications with result, sometimes different from that planned by policymakers, especially when it comes to small and mediumsized cities. The work was based on bibliographical, documentary, and electronic research aimed at understanding the reflexes of the University in the municipality. Currently, universities make a great contribution to socioeconomic development and the UFRB has great relevance in the current context of economic dynamization of the municipality of Cachoeira, of valorization of local culture and dissemination of knowledge. In this way, the article present brings new possibilities for reflection and understanding about the role and performance of UFRB in the Recôncavo, and its contribution to local development, considering that it is in the interest of society and managers to achieve effectiveness with the actions carried, bringing benefits for more people.
\end{abstract}

Keywords: Development. Public Policy. University. Recôncavo Baiano.

Políticas públicas de educación superior y desarrollo local: las transformaciones en el municipio de Cachoeira/Ba después la implantación de la Universidad Federal del Recôncavo de Bahía

\section{Resumen}

En este trabajo se analiza la importancia de la Universidad Federal del Recôncavo de Bahía UFRB en el proceso de desarrollo del municipio de Cachoeira, fruto de política pública nacional para la expansión de la enseñanza superior en el país, pero que al materializarse en el espacio promovió transformaciones, adaptaciones y recalificaciones con resultado, a veces, diverso de lo planeado por los formuladores de la política, principalmente cuando se trata de pequeñas y medianas ciudades. El trabajo se utilizó de investigación bibliográfica, documental, electrónica para comprender los reflejos de la Universidad en el municipio. En la actualidad, las universidades ejercen una gran contribución al desarrollo socioeconómico y la UFRB tiene gran relevancia en el actual contexto de dinamización económica del municipio de Cachoeira, de valorización de la cultura local y de diseminación del conocimiento. De esta forma, el artículo trae nuevas posibilidades para la reflexión y de entendimiento sobre la función y la actuación de la UFRB en el Recôncavo, y su contribución al desarrollo local, considerando que es de interés de la sociedad y de los gestores alcanzar efectividad con las acciones realizadas, trayendo beneficios sociales para un mayor número de personas.

Palabras-Clave: Desarrollo. Políticas Públicas. Universidad. Recôncavo Baiano.

\section{Introdução}

A presença de uma Universidade pública em uma localidade, principalmente em pequenas e médias cidades, gera um forte impacto nos setores econômico, social, educacional, cultural e político desses espaços, e isso é dependente da relação que a instituição mantém com a comunidade, uma vez que, quanto maior o nível de 
integração e cooperação que se dá entre instituição e sociedade, maiores se tornarão as transformações socioespaciais.

A implantação da UFRB no Recôncavo se dá dentro de um projeto de um projeto de democratização e interiorização da educação superior no Brasil. Ou seja, é resultado de uma política pública federal para o ensino superior do país e tem papel fundamental na região do Recôncavo da Bahia enquanto elemento-chave para o processo de desenvolvimento regional e local.

$\mathrm{Na}$ atual fase de organização da sociedade e da economia, caracterizada pela globalização e pelo período técnico-científico e informacional, as universidades possuem fortes desafios, como: atender às demandas por formação de profissionais mais capacitados ao mercado atual; indicar soluções para os problemas que afligem a vida em comum; continuar favorecendo o desenvolvimento cultural, político, econômico, social e ambiental de regiões e países, principalmente devido à contribuição que essas instituições podem dar no campo da ciência, tecnologia e da inovação.

Nesse contexto, necessário se faz avaliar o papel da Universidade enquanto fator de desenvolvimento local e de indutora de uma maior e melhor equidade no processo de inclusão socioespacial. Como exemplo, tem-se a implantação da UFRB no interior da Bahia, no modelo multicampi, e instalada em diversas cidades, como Cachoeira, Amargosa e Feira de Santana.

A problemática central deste artigo se coloca com a questão: a UFRB, como instituição de ensino superior, tem se constituído em vetor de desenvolvimento local para o município de Cachoeira?

A intenção é reconhecer a importância das políticas públicas de educação superior e sua relação com o desenvolvimento de localidades e regiões, além de, especificamente, qualificar o papel da UFRB como agente de desenvolvimento socioespacial.

\section{Desenvolvimento Local e Humano}

As concepções contemporâneas sobre desenvolvimento trazem discussões acerca de noções e aspectos relacionados às localidades, à participação da sociedade civil, aos conselhos, cidades, sustentabilidade, governança local, organizações do terceiro setor, organizações em rede, cidadania, entre outros.

O movimento que promoveu maior influência dos aspectos locais, internos e endógenos ao desenvolvimento de países e regiões, fortaleceu-se por importantes mudanças na economia internacional durante a década de 1970, motivado pelo enfraquecimento do modelo de produção industrial fordista, pelo baixo crescimento econômico mundial, pela revolução tecnológica, pelo fim do ciclo do Estado planejador com base na teoria keynesiana de gestão da macroeconomia dos países ocidentais e pelo enfoque na teoria neoliberal, que retoma a ideia de um mercado mais forte e independente do planejamento estatal. Além disso, o desenvolvimento até então proposto para os países subdesenvolvidos - baseado em planos governamentais de industrialização, de cima para baixo - como o realizado no Brasil, não refletiu em mudanças reais e sustentáveis nos índices de pobreza, além disso, ocorreram processos de concentração industrial que promoveram maior concentração de renda e desigualdades regionais. 
Desta forma, o desenvolvimento local, conforme sinaliza Lopes (2003), busca ser uma alternativa proativa e propositiva no contexto de internacionalização da economia mundial, da ideologia neoliberal e das diversas necessidades das populações de países que enfrentam graves problemas sociais como desemprego, exclusão social e baixo desenvolvimento tecnológico e educacional.

Conforme argumenta Lopes (2003):

os governos locais passam a surgir como um dos atores impulsionadores
do processo de desenvolvimento econômico local, empreendendo
iniciativas próprias e mais adequadas às particularidades de cada lugar
(LIMA; LOYOLA; MOURA, 2000). Aos governos estaduais, cabem a geração
de poupança pública local e a recuperação da capacidade de investimento.
Aos governos municipais, cabe coordenar as ações internas à cidade,
adequando-as às realidades regionais e até mundiais. (LOPES, 2003, p. 44).

É importante salientar que, para autores como Brose (2000) e Amaral Filho (2001), a atuação do Estado não pode ser negligenciada, pois as questões macroeconômicas da economia são fundamentais para promover a estabilidade econômica necessária para permitir que ações de cunho mais interno, porém conectadas com a economia nacional e global, possam ter as condições mínimas de desenvolvimento.

Segundo Brose (2000), o desenvolvimento na sua perspectiva local, como nas perspectivas humana e sustentável, ou qualquer que seja sua adjetivação, "depende de uma complexa, demorada e contínua interação e sinergia entre fatores econômicos, políticos, sociais e culturais para acontecer" (Brose, 2000, p. 10). Desta forma, o desenvolvimento não é fruto apenas do crescimento econômico ou das ações de um Estado centralizador e indutor de ações para o desenvolvimento de "cima para baixo", mas, também, das complexas e dinâmicas relações horizontais entre os diversos atores sociais, que se tornam fontes de poder para gerar uma rica participação da comunidade em prol de uma melhor qualidade de vida.

Esse modelo alternativo de desenvolvimento regional, que surge a partir das transformações econômicas e políticas que ocorreram no mundo, sob a lógica capitalista, é marcado pela ampliação de poder dos atores locais e na perspectiva da valorização das potencialidades socioeconômicas e humanas do território, no modelo de "baixo para cima".

Já o conceito de "desenvolvimento humano" se fortaleceu a partir dos Relatórios de Desenvolvimento Humano (RDH) e da criação do Índice de Desenvolvimento Humano (IDH), em 1990, em contraponto ao Produto Interno Bruto (PIB) per capita, tido como insuficiente para medir o desenvolvimento para além do crescimento econômico.

A base teórica que influenciou o paradigma do desenvolvimento humano utilizado por diversas organizações internacionais, como a Organização das Nações Unidas (ONU), para apoiar a construção de novas políticas públicas de combate à pobreza e à fome nos países pobres teve como fundamento as ideias defendidas pelo economista Amartya Sen. Para Sen (2007a), a qualidade de vida ${ }^{1}$ das pessoas deve ser

${ }^{1} \mathrm{O}$ conceito de qualidade de vida é abordado por diversas ciências e concebido de diversas formas, como sinônimo de saúde; satisfação com a vida, etc. As diversas definições também podem atribuir fatores subjetivos e objetivos, tornando-o ainda mais complexo. Conforme citam Pereira, Teixeira e 
considerada como o objetivo fundamental do processo de desenvolvimento. Portanto, ele considera que o crescimento econômico através do crescimento do PIB e da renda real não é suficiente para obter padrões de desenvolvimento que contemplem a melhoria de vida dos indivíduos, visto que a prosperidade econômica é um meio para qualificar a vida humana e não um fim em si mesma.

A abordagem trazida por Sen para falar sobre desenvolvimento humano é denominada de "capacidades humanas" e considera a vida humana como um conjunto de "fazeres e seres" ou funcionamentos. Deste modo, as capacitações refletem a liberdade que uma pessoa possui para escolher entre diversas possibilidades e modos de vida, ou seja, ser e fazer a partir de seus próprios valores, com o desenvolvimento passando a significar também um processo de expansão das possibilidades de escolha para o indivíduo, fazendo desta perspectiva de análise uma condição que pode ser utilizada para entender a complexa medida da qualidade de vida.

Um importante exemplo, com base na proposta de capacitações de Sen, enquanto base fundamental para a qualidade de vida, é a capacitação relacionada ao fator educação, ou seja, capacidade de ler e escrever, de cursar uma universidade, de desenvolver uma habilidade, de compreender melhor o mundo.

Enquanto a prosperidade econômica ajuda as pessoas a levarem vidas mais livres e plenas, da mesma maneira mais educação, cuidados de saúde, atenção médica e outros fatores influenciam positivamente as liberdades efetivas de que as pessoas desfrutam. Esses "desenvolvimentos sociais" devem ser diretamente computados como “desenvolvimentistas", já que eles nos ajudam a levar vidas mais longas, livres e proveitosas, somando-se ao papel que eles têm na promoção da produtividade, do crescimento econômico ou das rendas individuais. (SEN, 2007b, p. 93).

Neste sentido, a expansão da capacitação, notadamente pela educação, é fundamental para a mudança social, pois contribui, dentre outros benefícios, para o desenvolvimento social, para a diminuição da desigualdade de gênero e para aumentar e qualificar a participação popular em torno das decisões políticas.

O modelo de desenvolvimento humano difundido por organizações internacionais como o Banco Mundial e a ONU, com base nas concepções de Amartya Sen, passa por análises e críticas de autores nas áreas da economia e das ciências sociais. Mendonça (2012) afirma que este modelo, de concepção neoliberal, não é uma alternativa de enfrentamento para acabar com o subdesenvolvimento e as desigualdades no mundo, serve para melhorar alguns índices de qualidade de vida, mas não para acabar com a pobreza, a miséria e a fome.

As políticas públicas que são desenvolvidas pelos países com base neste modelo objetivam diminuir os índices de pobreza, mas não conseguem ser a solução para o problema, porque, dentre outros limites e incongruências, não consideram

Santos (2012, p. 244) os conceitos mais aceitos de qualidade de vida buscam incluir uma multiplicidade de dimensões, "O principal exemplo que pode ser citado é o conceito preconizado pela Organização Mundial da Saúde (OMS) no qual qualidade de vida reflete a percepção dos indivíduos de que suas necessidades estão sendo satisfeitas ou, ainda, que lhes estão sendo negadas oportunidades de alcançar a felicidade e a auto realização, com independência de seu estado de saúde físico ou das condições sociais e econômicas (OMS, 1998)". 
questões estruturais inerentes ao modelo econômico capitalista que, dentro da sua lógica de reprodução, mantém os países subdesenvolvidos numa condição dependente perante países mais ricos e com pouca margem para superar os limites que lhes são impostos, dentre outras razões, pelo baixo desenvolvimento tecnológico, pelas trocas comerciais desiguais e pela dependência financeira.

Além disso, a continuidade de políticas sociais de superação da pobreza - que têm por objetivo principal promover as condições necessárias para que os indivíduos possam desenvolver suas "capacidades" - não é possível em qualquer situação econômica; muitas vezes, limites são colocados aos gastos públicos, mesmo que isso cause danos àquelas políticas já em curso, tudo isso para não afetar um modelo de crescimento econômico que prioriza a manutenção das grandes riquezas, o aumento do lucro e diminuição dos custos, ainda que tal ação signifique piora das condições de trabalho, através do aumento da carga horária, da exigência por maior produtividade e/ou da diminuição dos salários dos trabalhadores.

O crescimento econômico é sempre a prioridade, enquanto as políticas sociais, mais do que estarem limitadas pelas necessidades do capital, justificam-se pelas próprias especificidades, limites e potencialidades que o capital possui em cada sociedade. As instituições encarregadas de promover a justiça distributiva o fazem de acordo com as necessidades do capital e de modo a conferir o máximo de eficácia ao sistema de preços de mercado. As liberdades formais básicas é que determinam os limites que os indivíduos dispõem para realizar seus objetivos. Esta liberdade formal, entendida como função do aparato legal e das regras sociais e políticas em vigor, precede a realização dessas aspirações, sendo definidas a priori. Há aqui claramente uma posição idealista, que não condiz com os resultados produzidos no processo histórico de desenvolvimento capitalista. (MENDONÇA, 2012, p.68).

Para Mendonça (2012), os programas sociais em curso não resolvem a questão; no entanto, servem para dar condições a indivíduos ou a uma determinada parcela da sociedade de superar as condições iniciais de pobreza e exclusão, o que é de grande mérito. Porém, essas políticas não alteram as condições que tornam recorrentes a reprodução da desigualdade e da pobreza nos países periféricos.

Pinheiro (2012), ao realizar uma análise sobre a abordagem das capacidades de Sen, diz que:

[...] os citados estudos internacionais fornecem evidências empíricas de que a relação positiva entre o crescimento econômico e o aumento da expectativa de vida é magnificada quando o crescimento é apoiado por um conjunto de políticas públicas voltadas para o aumento das oportunidades sociais, tais como as políticas de educação básica, saúde, seguridade social, reforma agrária etc. Vale dizer, os países que cresceram com base em um sólido conjunto de políticas sociais (como é o caso geral dos países do Leste e do Sudeste Asiático nos últimos trinta anos), experimentaram um aumento da expectativa de vida de suas populações maior do que o de países que cresceram sem uma devida preparação social (Índia e Paquistão, por exemplo). Portanto, a experiência internacional nos apresenta indícios de que a expectativa e a qualidade de vida das populações são afetadas mais diretamente por certas políticas sociais (educação e saúde, dentre outras) do que pelo crescimento econômico puro e simples. (PINHEIRO, 2012, p.36). 
Portanto, construir e ampliar políticas públicas no sentido de fortalecer a educação, dentre outras políticas sociais, desde o ensino infantil até o ensino superior, seria essencial para promover o desenvolvimento humano e, consequentemente, melhorar a vida das pessoas em qualquer país, independentemente do regime político ou econômico.

\section{Desenvolvimento e educação superior}

Os benefícios da educação superior podem ter um caráter individual (melhoria do rendimento e da produtividade, aumento dos cuidados com a saúde e da participação comunitária) e social (redução da pobreza, abertura para debates conflituosos na sociedade: ambientais, de gênero, raça, etnia etc.), avanço científico e tecnológico, busca por liberdades individuais e coletivas, vantagens econômicas, ou seja, a atuação das universidades na sociedade pode ser vista em vários campos e através de várias ações.

Segundo Santos (2013, p. 33), a partir de um estudo realizado sobre desenvolvimento local focado na presença da Universidade Estadual de Santa Cruz (UESC) no bairro Salobrinho, em Ilhéus, observa-se a importância da Universidade, que é "fonte de conhecimento, de cultura e de compreensão política", como também é lócus para a transformação da sociedade. Além disso, pode contribuir para o desenvolvimento das comunidades locais através dos projetos de Estado desenvolvidos via Universidade e dos seus projetos de pesquisa e extensão. Mas, ainda segundo Santos (2013), a própria presença da Universidade já cria um ambiente para a atração de investimentos comerciais, favorecendo o desenvolvimento econômico e contribuindo para a transformação do espaço geográfico, provocando alterações ambientais, na ocupação humana, na estrutura urbana, no comércio local, entre outros.

A Universidade deve desenvolver o tripé ensino-pesquisa-extensão. Segundo ressalta Sobrinho (2005, p. 78), "São as universidades públicas as que mais produzem pesquisas e inovações tecnológicas que aumentam a produtividade geral e estão voltadas ao atendimento de problemas e necessidades que as sociedades apresentam". Ressalta-se, no entanto, que as universidades particulares e, em especial, as comunitárias também produzem pesquisas e projetos de interesse social, porém, em geral, sem estarem condicionadas a um excessivo zelo acadêmico, e caracterizadas por uma maior articulação com as comunidades locais.

Para Milton Santos, o atual período técnico-científico e informacional em que vivemos - no qual a técnica está unida com a ciência, tornando-se progressivamente um dado que carrega conteúdo informacional - tem tornado o mercado cada vez mais global: técnica, informação, ciência e tecnologia, formam, em conjunto, a base mais imprescindível para a existência do mercado global e da "produção, da utilização e do funcionamento do espaço e tendem a constituir o seu substrato" (SANTOS, 2009, p. 238). Nesse sentido, espaços dotados de maior conhecimento possuem mais força e recursos, pelo menos os de caráter econômico e produtivo, para superar possíveis dificuldades locacionais ou naturais, alcançando retornos mais lucrativos em relação a regiões ou locais desprovidos de instrumentalização técnica e científica. 
Portanto, na atual proclamada "sociedade do conhecimento", o crescimento econômico está vinculado ainda mais com o desenvolvimento científico e tecnológico; no entanto, a forma desigual de acesso aos fatores de geração de riqueza entre pessoas, lugares e nações é uma das causas que geram processos de desigualdade socioeconômica. Nesse sentido, o acesso desigual ao conhecimento e aos processos de geração e reprodução da ciência e da tecnologia também instauram dinâmicas que geram desigualdades e exclusão.

Neste contexto, países, como o Brasil, - que, ao longo do tempo, têm sofrido com problemas gerados por crises econômicas e políticas, com reflexos históricos nas condições de pobreza e desigualdade social - têm um desafio ainda maior para criar condições estruturais e desenvolver uma cultura universitária, de ciência e tecnologia no país e, consequentemente, gerar processos de inovação necessários às constantes e rápidas mudanças do mercado e da sociedade.

Assim, perante a perspectiva de entender a educação enquanto um direito social com poder de desenvolver as capacidades humanas, seus valores e possibilidades, com benefícios individuais e coletivos, é fundamental e imprescindível fortalecer a Universidade pública.

\section{Políticas públicas de expansão da educação superior no Brasil}

A recente expansão da educação superior no Brasil, a partir do primeiro mandato do governo do ex-presidente Luiz Inácio Lula da Silva (LULA) (2003-2007), foi construída a partir de ações no sentido de aumentar o número de matrículas na educação superior e garantir a democratização do acesso à Universidade. A ação do Estado foi norteada por políticas públicas voltadas para resolver, entre outros, o problema do atraso produtivo e tecnológico que o país enfrentava devido ao baixo nível de acesso, por parte da maior parte dos jovens brasileiros, à educação superior, um grave problema nacional que ainda persiste.

Nesse sentido, foram implementados programas como: o Programa Universidade para Todos - PROUNI, o Fundo de Financiamento ao Estudante de Ensino Superior - FIES, o Programa de Apoio a Planos de Reestruturação e Expansão das Universidades Federais - REUNI, a Universidade Aberta do Brasil - UAB, o Sistema de Seleção Unificada - SISU, a Rede Federal de Educação Profissional Científica e Tecnológica e criou os Institutos Federais de Educação, Ciência e Tecnologia - IFs. Esses programas objetivavam contribuir para atender as metas do Plano Nacional de Educação - PNE, Lei nº 10.172 de janeiro de 2001, que, entre outros, visava prover, até 2010, a oferta de educação superior para, pelo menos, 30\% da população na faixa etária entre 18 e 24 anos (ARRUDA, 2011), mas que não alcançaram ao final da década (2001 - 2011) os resultados conforme o pretendido pelo plano de metas.

As ações e programas resultaram na expansão do setor privado, mas também no aumento das vagas na rede pública. Tal situação decorreu das pressões sociais por mais educação para as classes menos favorecidas, mas também do poder exercido pelo mercado sobre ações desenvolvidas pelo Estado. Assim, da necessidade de tornar o setor produtivo brasileiro mais competitivo, dentro do contexto da administração neoliberal, o qual passa a ditar o sistema capitalista mundial e influenciar o papel exercido por Estados-nações como o Brasil, o governo Lula (2003 - 2007) efetivou seu projeto para a educação superior - intitulado "Uma Escola do 
Tamanho do Brasil" -, que, primeiramente, direcionou recursos e esforços no sentido de expandir cursos e vagas na educação superior via iniciativa privada e, posteriormente, via setor público, especialmente com a criação do REUNI, em 2007.

Mancebo, Vale e Martins (2015, p.34), ao discutirem as políticas de expansão da educação superior entre os anos de 1995 e 2010, ressaltam a grande expansão do setor privado no cenário de crescimento da educação superior, cujo número de matrículas cresceu 347,15\%, entre 1995 e 2010; já no setor público, a expansão no mesmo período foi de $134,58 \%$. Os autores, ao apresentarem tais índices, ressaltam que isso é, em parte, resultado do contexto internacional, marcado pelas políticas neoliberais e a globalização, mas também é devido à perpetuação de um discurso ideológico que tenta explicar a condição do Brasil, país marcado pelas desigualdades e pela pobreza, como resultado da baixa educação recebida por seus cidadãos. Assim, o discurso serviria, às vezes, muito mais como lobby do mercado educacional para conseguir expandir o setor, sem, no entanto, oferecer qualidade ou, ao menos, cursos e produção científica que permitissem resultados mais significativos para o desenvolvimento das cidades ou da nação.

Mais adiante, os autores ressaltam que a questão do desenvolvimento não pode ser explicada unicamente pela situação dos padrões educacionais de uma sociedade. O processo histórico da produção da desigualdade - construído a partir das desiguais relações comerciais entre nações, das guerras, da escravidão, da colonização etc. - fornece explicações mais reais e profundas para esse fato do que aquelas que o mero discurso político e/ou o viés mercadológico nos fazem, por vezes, acreditar e que direcionam o processo de elaboração das políticas públicas para o interesse privado.

Traçando uma abordagem sobre os conceitos de "políticas públicas", Arruda (2011, p. 503) cita várias definições, entre elas: "Azevedo (1997) pontua que as políticas públicas constituem o ‘Estado em Ação' e que elas revelam o projeto de sociedade em implementação”. Assim, Arruda (2011), após considerar os conceitos de políticas públicas de autores como Muller e Surel, e Azevedo, esclarece que:

\footnotetext{
Dessa forma, considerando a existência de uma demanda reprimida pleiteando o ingresso na educação superior, incorpora-se a agenda das prioridades do governo Luís Inácio Lula da Silva, a preocupação em torno da política de expansão da educação superior e de ampliação do acesso que se voltam tanto para o setor privado quanto para o setor público, priorizando a democratização da educação superior de grupos sociais tradicionalmente excluídos desse nível de ensino. (ARRUDA, 2011, p. 503).
}

Heidemann (2014) cita dois importantes autores ao tratar sobre conceitos de Políticas Públicas (PP), o cientista político Thomas R. Dye e William Jenkins. Assim, para Dye (1972), a "política pública é tudo o que os governos escolhem fazer ou deixar de fazer" (HEIDEMANN, 2014, p.31); e, para Jenkins, conforme análise de Howlett e outros autores, "a policy-making é um processo dinâmico e [é], em geral, o resultado de um conjunto de decisões inter-relacionadas". (HEIDEMANN, 2014, p.32).

Assim, o conceito de "política pública" vai além do sentido clássico, no qual o governo era o único agente de políticas. Outros atores ou public policy-makers (empresas, associações, sindicatos, igrejas, universidades etc.) entram na arena pública e realizam, junto com o governo, o processo da política pública: montagem 
da agenda política, formulação, tomada de decisão, implementação e avaliação, conhecidas como etapas do ciclo ou estágios de pollicy-making.

Os autores Lascoumes e Le Galès (2012) também ressaltam que a concepção de "política pública" atribuída apenas à ação estatal está ultrapassada, visto que, outros atores - tais como organizações não-governamentais, associações e instituições econômicas - têm forças para influenciar a concepção e as diretrizes de determinada política pública.

Outra interessante análise sobre as políticas públicas que trazem esses autores está inserida no argumento de que o problema público é, antes de tudo, uma construção política a partir dos desafios públicos que estão em destaque pelos diferentes grupos que compõem a estrutura social. Assim, um problema se torna importante quando atores interessados passam a inscrevê-lo nos diversos espaços públicos.

\begin{abstract}
Um problema torna-se público a partir do momento em que os atores sociais estimam que algo deve ser feito para mudar uma situação. Ele torna-se político a partir do momento em que a solução almejada só pode ser dada pelo público. [...] A fortiori, o problema torna-se público quando a autoridade estatal se apropria de determinado desafio e o inscreve em sua agenda de ação. (LASCOUMES; LE GALÈS, 2012, p. 52).
\end{abstract}

Azevedo (2004) considera a educação uma política pública de corte social, a qual, portanto, insere-se num contexto em que atuam diversas forças (políticas, econômicas, culturais etc.) que influenciam a condução das ações pelo Estado para gerir a educação. Por exemplo, a partir da década de 1970, a abordagem neoliberal direcionou algumas decisões que influenciaram o rumo que a política educacional tomou no Brasil desde aquele momento. Induzidos pelo pensamento neoliberal, a crise econômica mundial no início dos anos 1970, o processo de globalização, a crise fiscal do Estado e as novas ideologias para a sua atuação (de agente indutor para regulador), influenciaram a visão sobre o papel da educação na sociedade. Nesse momento de reestruturação capitalista e da crescente importância advinda da ciência e tecnologia para o setor produtivo, a educação tornou-se essencial para a produtividade do trabalho e, consequentemente, para o crescimento do lucro, transformando-se em um fator central no cenário capitalista mundial.

O governo federal, nesse período, desenvolveu algumas ações para as políticas públicas de educação superior, no sentido de tornar o país mais preparado para se colocar diante dos novos desafios do desenvolvimento nacional. Para tanto, entre as ações planejadas, criaram-se novos cursos, campus e universidades, principalmente no interior do país; nesse processo, concretizou-se a criação da UFRB. 


\section{O REUNI e a Universidade Federal do Recôncavo da Bahia - UFRB}

As desigualdades sociais e regionais são marcas conhecidas da história brasileira desde o início da sua formação enquanto Estado-nação, e essa condição tem reflexos nítidos sobre a situação da educação superior brasileira, historicamente de caráter elitista e concentrador. O Plano Nacional de Educação (PNE) 2001-2011 (BRASIL, 2001) tratou desses problemas e definiu algumas ações para combater tal injustiça, que, continuamente, ainda se perpetua.

Para tanto, o governo federal promoveu diversas políticas públicas, dentre elas, o Programa de Apoio a Planos de Reestruturação e Expansão das Universidades Federais (REUNI), instituído pelo Decreto $\mathrm{n}^{\circ}$. 6.096, de 24 de abril de 2007, que foi uma das ações que integraram o Plano de Desenvolvimento da Educação - PDE, o qual pode ser entendido como um plano executivo do PNE e compõe a política nacional para a educação. O PDE tem como expressão principal enfrentar as desigualdades de oportunidades educacionais tendo em vista a relação existente entre educação e desenvolvimento, seja no âmbito social, econômico, regional ou local (BRASIL, 2007a). A partir da concepção sobre educação superior contida no PDE, foram (re)elaboradas políticas públicas como: o REUNI, o Fundo de Financiamento ao Estudante do Ensino Superior (FIES), o Programa Universidade para Todos (PROUNI) e o Sistema Nacional de Avaliação da Educação Superior (SINAES).

Conforme Arruda (2011, p. 506), "para o MEC o REUNI é uma forma de incentivar as universidades públicas a retomarem seu papel estratégico e contribuir com o desenvolvimento econômico e social do país".

A expansão da Rede Federal de Educação Superior se iniciou em 2003 e elevou os números de municípios atendidos pelas universidades de 114 (em 2003) para 237 (até o final de 2011), sendo criadas 14 novas universidades e mais de 100 novos campi. (BRASIL, 2007b).

Todas as 54 universidades federais existentes optaram em participar do programa iniciado em 2008, incluindo a UFRB e a Universidade Federal do ABC (UFABC), criadas em 2005, dentro do Programa de Expansão Fase I das Universidades Federais. Atualmente, o país conta com 63 universidades federais, sendo que 18 foram criadas a partir de 2003. (BRASIL, 2016).

O REUNI, enquanto política pública com grande viés democratizante e territorial, priorizou a expansão de novas universidades e campi no interior do país, a fim de minimizar o grande déficit existente no acesso à educação superior por jovens com poucas possibilidades de cursar uma faculdade longe da sua região de origem ou nas universidades das capitais dos estados. No entanto, apesar de possuir méritos significativos para o crescimento da educação superior pública no Brasil, esse programa teve muitos problemas de execução ao longo dos anos e não escapou de críticas por parte do meio acadêmico, tal como a falta de tempo para a discussão do programa com a comunidade acadêmica e a sociedade sobre os cursos que poderiam melhor atender os diversos contextos regionais. 


\section{A UFRB no Recôncavo}

A Universidade Federal do Recôncavo da Bahia originou-se pela Lei nº 11.151 de 29 de julho de 2005, por desmembramento da Escola de Agronomia da Universidade Federal da Bahia (UFBA), incorporando todos os discentes e a estrutura do seu quadro de pessoal. (UFRB, 2009).

A implantação da UFRB no Recôncavo ocorreu a partir de uma ação estatal que esperava promover o desenvolvimento regional e local das cidades, e da sua zona de influência. Segundo consta no documento que tratou da criação da UFRB, intitulado "UFRB subsídios para a criação e implantação a partir do desmembramento da Escola de Agronomia da Universidade Federal da Bahia" (UFBA, 2003), a Universidade foi proposta com o formato multicampi, para atender a articulação do saber científico com a complexa realidade do Recôncavo, entrelaçando a Universidade e seus campi aos aspectos socioespaciais e ao contexto econômico, político, cultural, histórico e ambiental de cada subespaço regional.

No projeto, previram-se unidades da UFRB nas cidades de Cruz das Almas (sede), Amargosa, Cachoeira, Santo Antônio de Jesus, Santo Amaro da Purificação todas em funcionamento - e também nas cidades de Nazaré das Farinhas e Valença, estas que, até o momento, não se concretizaram; no entanto, foi criado mais um centro de ensino, na cidade de Feira de Santana.

Conforme esclarecem Santana e Marengo (2012), as cidades que receberam centros de ensino da UFRB possuem alguma capacidade de polarização na região (possuem, mesmo que de forma incipiente, algum tipo de Arranjo Produtivo Local APL em desenvolvimento). Por exemplo, a cidade de Santo Antônio de Jesus é um centro polarizador devido à importância do setor terciário (serviços e comércio), considerado uma atividade motriz. Outro exemplo é a cidade de Cachoeira, onde o turismo, mesmo que desenvolvido precariamente, é uma atividade econômica essencial ao município e com potencial efeito polarizador.

\footnotetext{
O foco de atendimento dessas mesorregiões deve-se principalmente à perspectiva de descentralização dos polos educacionais das capitais no sentido de permitir o acesso das populações mais distantes ao ensino superior público, e como política dinamizadora de APL (Arranjo Produtivo Local) e desenvolvimento regional. (MARQUES; CEPÊDA, 2012, p. 185)
}

À medida que se criavam novas dinâmicas - com a instalação da UFRB e seus equipamentos, com a vinda de pessoas (servidores públicos e alunos), de recursos financeiros, com a expansão da rede elétrica, de comunicações e de transporte, e, consequentemente, com o surgimento de novas funcionalidades para estruturas e equipamentos tradicionais ou abandonados - a vida nas cidades que receberam os Centros se reestruturava, implicando em uma nova configuração, trazendo dinamismo para a economia local, criando, porém, tensões e conflitos socioculturais.

Santana (2012) ressalta que a instalação da UFRB causa conflitos de interesses entre diversas lideranças políticas locais daqueles municípios que lutavam para sediar um núcleo da Universidade. Lideranças econômicas, políticas e sociais passaram a promover uma ação de mobilização da população para dar visibilidade à questão, visto que a instalação de uma instituição universitária é entendida, por parte dos grupos de interesse, como um elemento de desenvolvimento e de dinamização da 
economia e da estrutura urbana local, podendo então trazer diversos tipos de benefícios à localidade.

Estas lideranças político-partidárias sempre vinculam a presença da universidade na cidade ao dito "desenvolvimento local e regional" e a um efeito imediato sobre a dinâmica econômica das cidades. Muitos destes políticos partidários têm o apoio de outras lideranças da sociedade civil: professores, associações, sindicatos, as quais, por sua vez, mobilizam a opinião pública a fim de reivindicar para si um campus. (SANTANA, 2012, p.68)

Contudo, Santana e Marengo (2012), ao comentarem sobre o processo de implantação da UFRB, questionam o processo de supervalorização dos imóveis na cidade de Santo Antônio de Jesus, criando uma situação de exclusão da população mais empobrecida. Sobre isso, os autores questionam se houve alguma referência da implantação do campus no plano diretor da cidade, que servisse de apoio para ações que pudessem lidar com as possíveis consequências deste fato.

A preocupação com o desenvolvimento da região onde está inserida demonstra que a implantação da UFRB deve ser entendida enquanto uma política pública que busca, por meio da expansão e interiorização do ensino superior, ser um mecanismo para dinamização e o desenvolvimento da Bahia, do Recôncavo Baiano e das cidades onde os campi se instalaram. No Plano de Desenvolvimento Institucional (PDI) da UFRB, consta que a Universidade:

deve contribuir para o processo de desenvolvimento do Recôncavo da Bahia, do Estado e do País, realizando o estudo sistemático de seus problemas e a formação de quadros científicos e técnicos em nível de suas necessidades e aprofundar a integração da universidade com os municípios do Recôncavo e do Estado da Bahia para a promoção do desenvolvimento socioeconômico e cultural. (UFRB, 2009, p. 14 e 15).

Ainda sobre a implantação dessa política nacional no contexto local, Santana e Marengo (2012) analisam que:

não se pode esquecer que as ações verticais vindas das instâncias políticas federais dificilmente se realizam intactas nos lugares, visto que precisam ser negociadas com os agentes locais. As ações verticais encontram solidariedades locais - horizontalidades - que tanto podem oferecer atritos, obstáculos, ao desenvolvimento dessas ações, como não. De qualquer modo, o projeto nunca se concretizou intacto - o que se tornaria extremamente desorganizador daquelas horizontalidades preexistente e presumivelmente impraticável - mas se realiza modificado, adaptado às conveniências de uma elite local, ou das elites locais, e readaptados às necessidades daqueles que vivem no ambiente. No fim, o que se vê, as paisagens resultantes, assim como as dinâmicas que se animam, não traduz uma ordem local, tampouco uma ordem distante, mas sempre uma ordem possível (SANTOS, 2008), resultado da interação entre ambas. É dessa forma que se pode questionar o quanto é estratégico, para o desenvolvimento regional pensado pelo governo federal, o estabelecimento destes campi nas cidades referidas e o quanto é dependente de conveniências políticas locais, que não são tão integradas assim, como se pode presumir. (SANTANA; MARENGO, 2012, p. 47 e 48). 
Assim, ao longo da história de constituição do Recôncavo, diversas e sucessivas dinâmicas externas organizaram a região, inclusive ditando as atividades endógenas dos diferentes subespaços que a compõem, num esforço de complementaridade, para atender as necessidades exógenas. Foi o que se viu desde o período colonial, no Recôncavo açucareiro, fumageiro e, também, com a extração do petróleo. Períodos que foram marcados pela exploração da mão de obra local, pela manutenção de privilégios da elite, pela dependência regional frente ao capital e ao mercado estrangeiro, à margem da pobreza da maior parte da população e da fragmentação que caracterizou a vida econômica e social dos diversos subespaços regionais.

\section{A UFRB em Cachoeira}

Inicialmente, o Centro de Artes, Humanidades e Letras (CAHL), da UFRB, situado em Cachoeira, ofereceu três cursos de graduação: Comunicação, História e Museologia, as aulas se iniciaram no dia 16 de outubro de 2006. Ao total, o CAHL possuía 123 alunos ativos no semestre de 2006.2, com 23 docentes e 5 técnicos administrativos. (UFRB, 2006, Relatório de Gestão).

O período de janeiro a dezembro de 2007 correspondeu ao primeiro exercício regular da UFRB, o orçamento autorizado para esse exercício, totalizava $\mathrm{R} \$ 43.232 .407,00$. No entanto, houve paralização das obras no campus de Cachoeira, face à restauração e ampliação das edificações do Quarteirão Leite Alves, realizadas por intermédio do Programa Monumenta, para a implantação do Centro de Artes, Humanidades e Letras, inviabilizando a execução do orçamento que cabia ao Centro. Nesse período, o CAHL possuía 236 alunos nos cursos de Comunicação, História e Museologia, do total de 1.619 alunos de toda a UFRB. (UFRB, 2007, Relatório de Gestão).

Atualmente, o Centro de Artes, Humanidade e Letras que está instalado nos municípios de Cachoeira e São Félix, conta com dez cursos de graduação (Artes Visuais, Ciências Sociais, Cinema e Audiovisual, Comunicação Social, Licenciatura e Bacharelado em Ciências Sociais, Licenciatura em História, Museologia, Serviço Social e Tecnologia em Gestão Pública) e três programas de pós-graduação (Programa de Pós-Graduação em Ciências Sociais: Cultura, Desigualdades e Desenvolvimento; Mestrado Profissional em História da África, da Diáspora e dos Povos Indígenas; e Programa de Pós-Graduação em Comunicação - Mídia e Formatos Narrativos, este iniciado em 2017). Mais recentemente, em setembro de 2018, a Coordenação de Aperfeiçoamento de Pessoal de Nível Superior (CAPES) aprovou a proposta do Mestrado em Arqueologia e Patrimônio Cultural do CAHL/UFRB, que seguirá para o Conselho Nacional de Educação, responsável pela autorização e reconhecimento do curso. Além disso, conta com um Programa de Doutorado Interinstitucional (DINTER), firmado com o Programa de Pós-Graduação em Serviço Social da Universidade Federal do Rio de Janeiro.

O Centro funciona em três prédios principais: no Quarteirão Leite Alves (prédio de aulas), no prédio administrativo Ana Nery e na Fundação Hansen Bahia. São 126 docentes, 36 técnicos-administrativos e 1.725 alunos matriculados em 2017 (UFRB, 2017). Esses dados evidenciam o crescimento do centro ao longo dos anos, 
principalmente em relação ao número de servidores, alunos e cursos oferecidos, mas, por outro lado, houve pouca expansão e melhorias em relação à infraestrutura física.

\section{0 município de Cachoeira (BA)}

Cachoeira está localizado na região do Recôncavo Baiano, a 111 km da capital de Salvador e a $46 \mathrm{~km}$ de Feira de Santana. Ocupa uma área de $395 \mathrm{~km}^{2}$, população estimada de 34.536 habitantes e com densidade demográfica de 81,03 hab./ km². (IBGE, 2016).

Até meados do século XIX, Cachoeira exerceu grande influência econômica, sendo considerado um dos municípios mais ricos e populosos do país, e, até meados do século XX, exerceu um papel articulador na Região e no Estado perante outras cidades do Recôncavo. Porém, com as crises da agroindústria açucareira e fumageira, a chegada da Petrobrás em meados do século XX (Cachoeira não fazia parte dos municípios produtores) e, posteriormente, a mudança na estrutura dos transportes, com o asfaltamento das BR 101 e BR 324, localizadas distantes da estrutura urbana de Cachoeira, alterou-se o modo de transportar mercadorias, causando uma nova crise na economia da cidade, devido ao esvaziamento do seu porto marítimo e à desarticulação do transporte ferroviário.

A partir da década de 1980, surgiram políticas públicas estaduais de financiamento do potencial turístico da Cidade, com base na sua riqueza material e imaterial, iniciando um processo de desenvolvimento, ou, no máximo, de crescimento econômico, por meio do investimento em turismo cultural, incluindo, nesse processo, não só o acervo arquitetônico, mas também o turismo étnico.

Porém, só mais recentemente, a partir do Programa Monumenta, Cachoeira passou a receber maiores investimentos relacionados com as políticas públicas na área da cultura e do patrimônio, iniciando uma maior dinâmica econômica, advinda do incremento de recursos e do turismo na cidade. O Programa Monumenta, do Governo Federal, para preservação de cidades históricas, é de responsabilidade do Instituto do Patrimônio Histórico e Artístico Nacional (IPHAN) e iniciou suas ações na Cidade em 2002, recuperando inúmeros imóveis públicos e privados.

Além disso, o patrimônio imaterial de Cachoeira também passou a ser mais protegido, com o reconhecimento e tombamento de Terreiros de Candomblé e com o reconhecimento dos grupos de samba de roda do município como patrimônio imaterial, pelo IPHAN e pela Organização das Nações Unidas para a Educação, a Ciência e a Cultura (UNESCO). Outro investimento importante na área do patrimônio histórico e cultural veio do Governo do Estado da Bahia, junto com o Ministério do Turismo: o Programa de Ação do Turismo Étnico Afro da Bahia, com o objetivo de potencializar o turismo nesse segmento, contribuindo para fortalecer a economia com base na atividade do turismo que se tem desenvolvido na cidade. (HENRIQUE, 2009).

Ao tratar sobre esses programas, que têm fortalecido a economia de Cachoeira e também reorganizado o espaço e a vida na cidade, Henrique (2009) alerta para o fato de que os benefícios dessa reestruturação tendem a ser apropriados por uma pequena parte da sociedade, deixando à margem a população mais carente, visto que, no capitalismo, os espaços são produzidos pela lógica do lucro e seguindo as regras do mercado. Porém, as políticas públicas precisam ser 
planejadas para incluir e beneficiar toda a comunidade, evitando sua apropriação por uma minoria, que, nesse caso, se dá principalmente devido ao processo de especulação imobiliária.

Outro importante fator responsável por dinamizar a economia da cidade de Cachoeira foi a instalação de um Centro de ensino da UFRB, que, juntamente com outras políticas públicas, como o Programa Monumenta, impulsionaram a retomada do crescimento na cidade a partir de meados da primeira década do século XXI. A chegada do CAHL, com os novos servidores e estudantes, criou várias demandas na cidade, como transporte, hospedagem, alimentação, moradia, lazer etc., alterando a estrutura do comércio e dos serviços até então existentes no município.

As transformações se processaram no sentido de atender as necessidades dos novos consumidores e usuários, resultando em um processo de modernização dos espaços e alterando o cotidiano dos seus antigos moradores. É perceptível notar em Cachoeira, desde a instalação do CAHL, a abertura de pequenos estabelecimentos comerciais, supermercados, restaurantes, novas casas para aluguel, franquias etc.

\subsection{Perfil Econômico}

Com base em fontes de dados de instituições oficiais, como IBGE (Instituto Brasileiro de Geografia e Estatística), SEI (Superintendência de Estudos Econômicos e Sociais da Bahia) e TCM (Tribunal de Contas dos Municípios do Estado da Bahia), apresenta-se um retrato superficial da situação econômica do município de Cachoeira nos últimos anos, principalmente a partir do início do século XXI, período que marca a retomada do crescimento econômico da cidade, devido à chegada da UFRB em 2006 e o incremento de políticas públicas na área de preservação do Patrimônio Histórico e Cultural e turismo. Além destes, no início do ano de 2000, instalou-se, no município de Cachoeira, a uma distância de aproximadamente 5 quilômetros da sede municipal, o polo de curtimento e acabamento de couro da Mastrotto Brasil S/A, localizado na BR 101, km 201, em Capoeiruçu.

Ao comparamos o PIB de Cachoeira do ano de 2013 ao do ano de 2000, é possível constatar um forte crescimento, da ordem de 532\%, conforme Tabela 1 . Com relação a 2005, o crescimento foi de 175\%. Quanto aos dados de PIB per capita, os valores encontrados a partir de 2010 mostram um crescimento de $4 \%$ desse índice, se comparado aos de 2013. Assim, analisando-se os dados da Tabela 1, nota-se o crescimento do PIB de Cachoeira ao longo dos anos, o que demostra que o município vive um novo período de ascensão econômica. (IBGE, 2016).

Nota-se também um crescimento substancial do setor de serviços durante todo o período demonstrado, comparando-se o ano de 2013 com o de 2005, o crescimento foi de $84 \%$; e, com o ano de 2010, o crescimento foi de aproximadamente de $53 \%$, isso sem contar os serviços públicos (administração, saúde e educação públicas e seguridade social), que também cresceram aproximadamente $53 \%$, quando comparados no mesmo período de 2010 e 2013 - assim como ocorre no Brasil, o setor terciário tem significativa participação no crescimento do PIB de Cachoeira. (IBGE, 2016).

Tabela 1 - Valor Adicionado, PIB e PIB Per Capita a preços correntes do município de Cachoeira, Estado da Bahia, entre 2000 - 2013 em mil reais 


\begin{tabular}{|c|c|c|c|c|c|c|c|}
\hline \multirow[t]{2}{*}{ Ano } & \multicolumn{4}{|c|}{ Valor Adicionado bruto a preços correntes } & \multirow[b]{2}{*}{$\begin{array}{l}\text { Impostos } \\
\text { sobre } \\
\text { produtos } \\
\text { líquidos de } \\
\text { subsídios a } \\
\text { preços } \\
\text { correntes }\end{array}$} & \multirow[t]{2}{*}{ PIB } & \multirow{2}{*}{$\begin{array}{c}\text { PIB Per } \\
\text { Capita (R\$ } \\
1,00)\end{array}$} \\
\hline & $\begin{array}{l}\text { Agropecu } \\
\text { ária }\end{array}$ & Indústria & Serviços & $\begin{array}{c}\text { Administraçã } \\
\text { o, saúde, e } \\
\text { educação } \\
\text { públicas e } \\
\text { seguridade } \\
\text { social }\end{array}$ & & & \\
\hline 2000 & 13.186 & 6.952 & 38.054 & - & 3.300 & 61.492 & - \\
\hline 2005 & 10.973 & 50.092 & 70.077 & - & 10.169 & 141.310 & - \\
\hline 2010 & 18.107 & 178.364 & 84.183 & 52.316 & 17.610 & $350.581 *$ & $\begin{array}{c}\text { 10.943,68/ } \\
\text { hab. }\end{array}$ \\
\hline 2013 & 24.409 & 129.132 & 128.985 & 80.158 & 25.956 & $388.640 *$ & $\begin{array}{c}11.349,14 / \mathrm{h} \\
\text { ab. }\end{array}$ \\
\hline
\end{tabular}

Fonte, IBGE (2016).

* NOTA: Os dados do Produto Interno Bruto dos Municípios para o período de 2010 a 2013 (série revisada) têm como referência o ano de 2010, seguindo, portanto, a nova referência das Contas Nacionais.

A agropecuária do município de Cachoeira compõe-se, principalmente, pelas lavouras de cana-de-açúcar, mandioca, cítricos, maracujá, dendê, coco-da-baía, cacau, batata-doce, além da extração de madeira/lenha e da castanha de caju etc. A produção de animais compõe-se, principalmente, pelas aves, bovinos, ovinos, suínos e seus derivados leite e ovos, além da aquicultura (ostras, vieiras e mexilhões) e alevinos.

No setor industrial, destaca-se uma fábrica de beneficiamento e exportação de couro, as indústrias de couro para calçados, algumas fábricas de charutos, laticínios, e derivados da cana-de-açúcar.

No entanto, é o setor terciário, incluindo a prestação de serviços públicos, que mais contribui para o crescimento da economia local. O município dispõe de uma Universidade pública (a UFRB/CAHL) e uma faculdade particular (a Faculdade Adventista da Bahia), um hospital público, escolas públicas e particulares, serviços de hotelaria, farmácias, lojas de calçados, vestuários, perfumaria e construção, lojas de conveniências, supermercados, bares e restaurantes. O turismo cultural (visitação ao patrimônio arquitetônico, festas populares, religiosas e literárias etc.) é uma das principais fontes de geração de renda local.

As Tabelas 2, 3 e 4 expressam o crescimento econômico e financeiro do município de Cachoeira a partir de 2006. Na Tabela 2, demonstram-se as receitas orçamentárias do município de Cachoeira e, especificamente, a receita corrente tributária, proveniente da arrecadação de impostos, taxas e contribuições de melhoria, a qual se configura como uma importante fonte de arrecadação de receitas do Município para o custeio de suas finalidades públicas. O crescimento da receita corrente tributária do ano de 2010 em relação à de 2006, ano de início de funcionamento da UFRB em Cachoeira, foi de 169\%. Em 2015, observa-se uma forte queda da receita tributária quando comparado a 2010, o que pode ser um reflexo da crise econômica que o país tem enfrentado desde o ano de 2014 até então. (IBGE, 2016; TCM, 2016).

Tabela 2 - Finanças públicas: receita orçamentária corrente e corrente tributária em Cachoeira 2006; 2010; 2015 em reais 


\begin{tabular}{|c|c|c|}
\hline ANO & $\begin{array}{c}\text { Receitas orçamentárias } \\
\text { correntes }\end{array}$ & Receita corrente Tributária \\
\hline 2006 & $20.684 .197,38$ & $1.140 .458,40$ \\
2010 & $33.670 .167,67$ & $3.068 .611,17$ \\
2015 & $54.293 .347,36$ & $1.846 .458,33$ \\
\hline
\end{tabular}

Fonte: IBGE, 2016 e TCM/BA, 2016.

A Tabela 3 apresenta um crescimento dos números de empresas e de pessoal ocupado, com carteira assinada, no ano de 2010, quando comparado ao ano de 2006, e uma queda, do ano de 2010 para 2014, tanto do número de empresas como do número de empregados na economia formal. (IBGE, 2016).

Tabela 3 - Cadastro de empresas e pessoal ocupado em Cachoeira Bahia, 2006; 2010; 2014

\begin{tabular}{|c|c|c|}
\hline ANO & Estabelecimentos locais & Pessoal ocupado total \\
\hline 2006 & 420 & 3.100 \\
2010 & 699 & 3.911 \\
2014 & 466 & 3.873 \\
\hline
\end{tabular}

Fonte: IBGE, 2016.

Com relação às operações bancárias no Município, não houve um aumento no número de instituições bancárias entre 2006 e 2015, mas ocorreu um crescimento substancial das operações bancárias - como operações de crédito, poupança e depósito a prazo - em todo o período contido na Tabela 4. Isso revela uma melhora do desempenho da economia de Cachoeira ao longo desses últimos anos. (IBGE, 2016).

Tabela 4 - Instituições financeiras e operações bancárias em reais, Cachoeira Bahia 2006; 2010; 2013; 2015

\begin{tabular}{|c|c|c|c|c|}
\hline ANO & $\begin{array}{c}\text { Instituições } \\
\text { financeiras }\end{array}$ & $\begin{array}{c}\text { Operações de } \\
\text { crédito }\end{array}$ & Poupança & Depósito à prazo \\
\hline 2006 & 3 & 20.136 .254 & 21.463 .798 & 3.362 .049 \\
2010 & 3 & 43.129 .358 & 44.363 .601 & 10.636 .414 \\
2013 & 3 & 67.475 .863 & 70.147 .816 & 14.501 .985 \\
\hline
\end{tabular}

Fonte: IBGE, 2016. 


\subsection{Perfil demográfico e Social}

Conforme a Tabela 5, viviam 32.026 pessoas em Cachoeira em 2010. A projeção estimada para 2015 foi de 34.536 pessoas. Entre 2000 e 2010, a população do município cresceu a uma taxa média anual de $0,52 \%$ e a taxa de urbanização do município diminuiu de 52,05\% para 51,17\%, verifica-se, pois, que existe um equilíbrio entre a proporção de habitantes da zona urbana e da zona rural cachoeirana. As mulheres, em 2010 representavam $51,75 \%$ da população e os homens $48,25 \%$. (IBGE, 2016).

Tabela 5 - Censo demográfico Cachoeira - Bahia, 2000 e 2010

\begin{tabular}{|c|c|c|c|c|c|}
\hline ANO & População & Masculino & Feminino & Rural & Urbana \\
\hline 2000 & 30.416 & 14.885 & 15.531 & 14.585 & 15.831 \\
2010 & $\mathbf{3 2 . 0 2 6}$ & 15.453 & 16.573 & 15.639 & 16.387 \\
\hline
\end{tabular}

Fonte: IBGE, 2016.

O Índice de Desenvolvimento Humano Municipal (IDHM) de Cachoeira, em 2010, foi de 0,647 (Tabela 6), colocando o município na faixa de Desenvolvimento Humano Médio (IDHM entre 0,600 e 0,699). Cachoeira ocupa a 3.172 ${ }^{\mathrm{a}}$ posição entre os 5.565 municípios brasileiros, segundo o IDHM, e a $43^{\mathrm{a}}$ posição entre os 417 municípios do estado da Bahia. A dimensão que mais contribuiu para o IDHM do município foi Longevidade (com 0,762 de índice), seguida de Renda (0,615), e de Educação $(0,577)$. O IDHM do Estado da Bahia nesse mesmo ano foi de 0,660 , sendo que a dimensão renda foi de 0,663; longevidade, 0,783; e educação, 0,555. Assim, o índice da dimensão Educação do IDHM de Cachoeira foi maior que a do Estado. (ATLAS DO DESENVOLVIMENTO HUMANO DO BRASIL, 2016).

A taxa de crescimento do IDHM de Cachoeira entre 2000 e 2010 foi de 25,39\%, o índice passou de 0,516 em 2000 para 0,647 em 2010. Nesse período, foi a dimensão Educação, em termos proporcionais, que mais contribuiu para o crescimento do IDHM do município, passando de 0,375 (em 2000) para 0,577 (em 2010). A dimensão longevidade - a esperança de vida ao nascer - passou de 65,51 anos (em 2000) para 70,72 anos (em 2010), e a dimensão renda apresenta uma taxa média anual de crescimento de 4,49\%, entre 2000 e 2010, passando de $R \$ 239,23$ (em 2000) para R\$ 368,11 (em 2010). (ATLAS DO DESENVOLVIMENTO HUMANO DO BRASIL, 2016).

Tabela 6 - IDHM (renda, longevidade e educação) em Cachoeira em 1991, 2000 e 2010

\begin{tabular}{|c|c|c|c|c|}
\hline ANO & IDHM & RENDA & LONGEVIDADE & EDUCAÇÃO \\
\hline 1991 & $\mathbf{0 , 3 9 9}$ & 0,481 & 0,585 & 0,226 \\
2000 & $\mathbf{0 , 5 1 6}$ & 0,546 & 0,675 & 0,372 \\
2010 & $\mathbf{0 , 6 4 7}$ & 0,615 & 0,762 & 0,577 \\
Fonte: Atlas do Desenvolvimento Humano do Brasil, 2016.
\end{tabular}

Outros dados retirados do site Atlas do Desenvolvimento Humano do Brasil (2016) e SEI (BAHIA, 2016) também trazem informações relevantes sobre a evolução da condição de vida da população de Cachoeira entre os anos de 2000 e 2010, como 
melhoria na taxa de analfabetismo da população de 15 anos ou mais de idade, a qual reduziu de 20\% (em 2000) para 15,9\% (em 2010). Houve, nesses dez anos, uma redução de analfabetos, mas são índices ainda muito elevados: a taxa de analfabetismo da população urbana reduziu de $13,4 \%$ para $12,6 \%$ e a rural reduziu, no mesmo período, de $27,8 \%$ para 19,6\%. (ATLAS DO DESENVOLVIMENTO HUMANO DO BRASIL, 2016).

A mortalidade infantil passou de 40,57 por mil nascidos vivos (em 2000) para 25,2 por mil nascidos vivos (em 2010). Já a parcela da população em domicílios com acesso a água encanada e banheiro passou de 50,92\% (em 2000) para 72,45\% (em 2010). (ATLAS DO DESENVOLVIMENTO HUMANO DO BRASIL, 2016).

Em relação ao quesito Trabalho e Renda, a população economicamente ativa ocupada aumentou de $55,24 \%$ (em 2000) para $64,65 \%$ (em 2010). A população economicamente ativa que estava desocupada reduziu de $18,84 \%$ (em 2000) para $11,90 \%$ (em 2010). A População em Idade Ativa de Cachoeira era de 27.147 em 2010 e a População Economicamente Ativa era de 14.956 pessoas. Sendo que, destes, 18,96\% trabalhavam no comércio e $36,27 \%$ no setor de serviços. Já a vulnerabilidade à pobreza reduziu de 75,77\% (em 2000) para 60,25\% (em 2010). (BAHIA, 2016).

\section{Considerações Finais}

A implantação da UFRB em Cachoeira, em 2006, dinamizou a economia e trouxe diversas externalidades positivas para a Cidade. Uma Universidade, além de promover investimentos, elevar a renda, a poupança e trazer recursos financeiros para a cidade onde se encontra, também é capaz de elevar e disseminar o conhecimento, promover a cultura e a arte, como também favorecer a participação política da comunidade, além de contribuir com inúmeras mudanças no modo de produzir, pensar e agir da sociedade. Todas essas contribuições são capazes de promover a melhoria de fatores, como: educação, saúde, trabalho e renda, consciência política e comunitária, condições ambientais, entre tantos outros fatores que são fundamentais para o desenvolvimento humano no âmbito local. Por tudo isso, o efetivo compromisso da UFRB com o local é tão importante e necessário, principalmente diante de um país cheio de desigualdades e contradições e, especificamente, por conta das precárias condições econômicas e sociais em que ainda vive grande parte da população do Recôncavo e da cidade de Cachoeira.

Com a implantação da UFRB no Recôncavo da Bahia a partir de 2005, concretizou-se uma ação estatal que esperava promover o desenvolvimento regional e local das cidades e da sua zona de influência.

Na medida em que se criaram novas dinâmicas - com a instalação da UFRB e seus equipamentos, com a vinda de pessoas (servidores públicos e alunos), de recursos financeiros, com a expansão da rede elétrica, de comunicações e de transporte e, consequentemente, com o surgimento de novas funcionalidades em estruturas e equipamentos tradicionais ou abandonados -, a vida nesses espaços se reestruturou, implicando em uma nova configuração, trazendo dinamismo para a economia local.

Ao longo da análise e do levantamento dos dados secundários, obtidos por meio de bibliografia, de documentos oficiais, de dados censitários e consultas a sites governamentais sobre Cachoeira, percebeu-se que a UFRB alterou a produção e o uso do espaço urbano e contribuiu, como principal agente, com o seu dinamismo 
econômico. É notório o fortalecimento da economia local, em grande parte motivado pela chegada da Instituição e visualmente perceptível pelo aumento dos empreendimentos comerciais e do oferecimento de novos serviços, como transporte, educação e saúde. Além disso, a UFRB tem sido de grande relevância para a valorização da cultura local, por meio das ações de pesquisa e extensão desenvolvidas pelo seu Centro de ensino.

Contudo, para cumprir o seu compromisso com o desenvolvimento local e regional, conforme preceitua a própria Universidade em seus documentos oficias, a UFRB, desde a sua instalação na região do Recôncavo, necessita contribuir, na medida de suas possibilidades e em parceria com outras instituições, com o avanço de outros indicadores, principalmente no que se refere à melhoria das condições de vida da população em geral, por meio da qualificação do trabalho e da produção, da valorização dos mecanismos de participação popular e da participação em projetos para melhorar a infraestrutura urbana e para um meio ambiente mais saudável.

As universidades públicas são agentes do desenvolvimento e de transformação dos espaços onde se instalam. Em regiões pobres e em pequenas e médias cidades, a exemplo de Cachoeira, a influência de uma Universidade torna-se ainda mais visível. A UFRB dinamizou as relações econômicas e alterou a estrutura e a organização espacial da cidade, modificando costumes e o modo de vida local, além de poder seguir contribuindo com uma maior disseminação do conhecimento.

\section{REFERÊNCIAS}

AMARAL FILHO. Jair do. A endogeneização no desenvolvimento econômico regional e local. Planejamento e Políticas Públicas, n. 23, jun. 2001. Disponível em: <http://www.ipea.gov.br/ppp/index.php/PPP/article/view/78/89>. Acesso em: 10 maio 2015.

ARRUDA, Ana Lúcia Borba de. Políticas da Educação Superior no Brasil: Expansão e Democratização: Um Debate Contemporâneo. Espaço do Currículo, v. 3, n.2, p. 501510, set. 2010/mar. 2011.

ATLAS DO DESENVOLVIMENTO HUMANO DO BRASIL. Cachoeira, Ba. Disponível em: <http://www.atlasbrasil.org.br/2013/pt/perfil_m/cachoeira_ba>. Acesso em: 15 jul. 2016.

AZEVEDO, Janete M. Lins de. A educação como política pública. 3.ed. Campinas, SP: Autores Associados, 2004.

BRASIL. Lei n. 10.172, de 09 de janeiro de 2001. Aprova o Plano Nacional de Educação (PNE) e dá outras providências. Brasília, 2001.

- Ministério da Educação (MEC). Plano de Desenvolvimento da Educação

(PDE): Razões, Princípios e Programas. Brasília, 2007a. Disponível

em:<http://portal.mec.gov.br/arquivos/livro/livro.pdf>. Acesso em: 28 jun. 2016. 
- Ministério da Educação (MEC). Reestruturação e Expansão das

Universidades Federais (REUNI): Diretrizes Gerais. Brasília, 2007b.

. Ministério da Educação (MEC). Reestruturação e Expansão das

Universidades Federais (REUNI): Expansão, 2010. Disponível em:<

http://reuni.mec.gov.br/expansão>. Acesso em: 04 maio 2016.

BROSE, Markus. Fortalecendo a Democracia e o Desenvolvimento Local: 103

experiência inovadoras no meio rural gaúcho. Santa Cruz do Sul: EDUNISC, 2000.

HEIDEMANN, Francisco G. Do sonho do progresso às políticas de desenvolvimento. In. HEIDEMANN, Francisco G; SALM, José Francisco (Org.). Políticas públicas e desenvolvimento: bases epistemológicas e modelos de análise. Brasília: Editora Universidade de Brasília, $3^{\mathrm{a}}$ ed., 2014.

HENRIQUE, Wendel. A instalação da UFRB, a ação do Programa Monumenta e o turismo étnico na reestruturação urbana e no cotidiano de Cachoeira- Ba: notas preliminares de pesquisa, 2009. Disponível em:<

http://www.portalseer.ufba.br/index.php/geotextos/article/view/3570>. Acesso em: 13 jul. 2016.

IBGE. Instituto Brasileiro de Geografia e Estatística. Cidades@. Disponível em:< http://www.cidades.ibge.gov.br/xtras/perfil.php?lang=\&codmun=290490\&search=b ahia|cachoeira>. Acesso em: 19 jul. 2016.

LASCOUMES, Pierre; LE GALÈS, Patrick. Sociologia da Ação Pública. Tradução de George Sarmento. Maceió: EDUFAL, 2012, 244 p.

LOPES. Roberto Paulo Machado. Universidade Pública e Desenvolvimento Local: uma abordagem a partir dos gastos da Universidade Estadual do Sudoeste da Bahia. Vitória da Conquista: Edições UESB, 2003.

MANCEBO, Deise; VALE, Andréa Araujo do; MARTINS, Tânia Barbosa. Políticas de Expansão da Educação Superior no Brasil 1995-2010. Revista Brasileira de Educação, v.10, n.60, jan./mar. 2015.

MARQUES, Antonio Carlos Henriques; CEPÊDA, Vera Alves. Um perfil sobre a expansão do ensino superior recente no brasil: aspectos democráticos e inclusivos. Perspectivas, São Paulo, v. 42, p. 161-192, jul./dez. 2012. Disponível em: <http://actacientifica.servicioit.cl/biblioteca/gt/GT33/GT33_CepedaVMarquesA.pdf>. Acesso em: 26 jun. de 2016.

MENDONÇA, Luiz Jorge V. Pessoa de. Políticas sociais e luta de classes: uma crítica a Amartya Sen. Porto Alegre: Textos \& Contextos, v. 11, n. 1, p. 65-73, jan./jul. 2012. 
PEREIRA, Érico Felden; TEIXEIRA, Clarissa Stefani; SANTOS, Anderlei dos. Qualidade de vida: Abordagem, conceitos e avaliação, 2012. Disponivel em:< http://www.scielo.br/pdf/rbefe/v26n2/07.pdf >. Acesso em: 05 fev. 2017.

PINHEIRO, Maurício Mota Saboya. As liberdades humanas como bases do desenvolvimento: uma análise conceitual da abordagem das capacidades humanas de Amartya Sen. Texto para Discussão, $\mathbf{n}^{\circ}$ 1794. Rio de Janeiro, IPEA, novembro, 2012. Disponível em:

<http://www.ipea.gov.br/portal/index.php?option=com_content\&view=article\&id=1 6421>. Acesso em: 17 fev. 2016.

SANTANA, Elissandro Trindade. A Universidade Federal do Recôncavo da Bahia e a Produção do Espaço Urbano-Regional. Dissertação (Mestrado). Instituto de Geociências, UFBA, 2012.

SANTANA, Elissandro Trindade de; MARENGO, ShantiNitya. A Universidade Federal do Recôncavo como Política de Desenvolvimento Regional no Espaço Intraurbano de Santo Antônio de Jesus. Geotextos, vol. 8, n. 2, dez. 2012. Disponível em:<http://www.portalseer.ufba.br/index.php/geotextos/article/viewArticle/6131>A cesso em: 02 jun. 2016.

SANTOS, José Ricardo Rosa dos Santos. Universidade Pública e Desenvolvimento Local: a presença da Universidade Estadual de Santa Cruz (UESC) no bairro do Salobrinho em Ilhéus, Bahia, no período de 1991 a 2008. Ilhéus: Editus, 2013.

SANTOS, Milton. A natureza do Espaço: Técnica e Tempo, Razão e Emoção. $4^{\mathrm{a}}$ ed. São Paulo: EDUSP, 2009.

SEN, Amartya. Desenvolvimento como expansão das capacitações. In: FUKUDAPARR, Sakiko; SHIVA KUMAR, A.K (Ed.) Desenvolvimento Humano: leituras selecionadas. Belo Horizonte: PUC Minas Virtual, PNUD, 2007a, p.43-61.

. Capital humano e capacitação humana. In: FUKUDA-PARR, Sakiko; SHIVA KUMAR, A.K (Ed.) Desenvolvimento Humano: leituras selecionadas. Belo Horizonte: PUC Minas Virtual, PNUD, 2007b, 91-95.

SOBRINHO, José Dias. Dilemas da educação superior no mundo globalizado: sociedade do conhecimento ou economia do conhecimento. São Paulo: Casa do Psicólogo, 2005.

TCM/BA - TRIBUNAL DE CONTAS DOS MUNICÍPIOS DO ESTADO DA BAHIA. Indicadores Municipais. Disponível em:< http://www.tcm.ba.gov.br/wpcontent/uploads/arquivos_antigos/IndicadoresRevisado-Janeiro2008.htm>. Acesso em: 15 jul. 2016.

UFBA - UNIVERSIDA FEDERAL DA BAHIA. UFRB: Subsídios para a criação e implantação a partir do desmembramento da Escola de Agronomia da Universidade 
Federal da Bahia, 2003. Disponível em:<

https://ufrb.edu.br/portal/images/historia/projeto-ufrb.pdf >. Acesso em: 04 jul. 2016.

UFRB. Centro de Artes, Humanidades e Letras (CAHL). Disponível em: < https://www.ufrb.edu.br/cahl/>. Acesso em: 13 nov. 2017.

. PDI - Plano de Desenvolvimento Institucional (2010-2014), 2009. Disponível em:< https://www.ufrb.edu.br/portal/images/legislacao/pdi-ufrb-2010-2014.pdf> . Acesso em: 04 mar. 2016.

. Pró- Reitoria de Planejamento - PROPLAN. Relatório de Gestão, 2006; 2007. Disponível em:< https://www.ufrb.edu.br/proplan/index.php/relatoriodegestao $>$. Acesso em: 06 e 07 jul. 2016.

Jorge Antonio Santos Silva. Professor Adjunto da Universidade Federal do Recôncavo da Bahia - UFRB. doutorado em Ciências da Comunicação pela Universidade de São Paulo (2004) - área de concentração e linha de pesquisa Turismo. Membro do Observatório Estadual de Economia Criativa da Bahia OBEC-BA. Membro do Grupo de Estudos de Economia Regional e Urbana GERURB.

Ozana Rebouças Silva. Graduada em Licenciatura em Geografia pela Universidade Estadual de Feira de Santana (2007) e pós-graduada no Mestrado Profissional em Gestão de Políticas Públicas e Segurança Social pela Universidade Federal do Recôncavo da Bahia (2017). Tem experiência na área de Geografia, com ênfase em desenvolvimento local, atuando, principalmente, nos seguintes temas: Educação, Políticas públicas, Gestão e desenvolvimento local.

\section{Submetido em: 15/02/2018}

\section{Aprovado em: 15/12/2018}

Como citar: SILVA, Jorge Antonio Santos; SILVA, Ozana Rebouças. Políticas públicas de educação superior e desenvolvimento local: as transformações no município de Cachoeira/Ba após a implantação da Universidade Federal do Recôncavo da Bahia.. Redes, Santa Cruz do Sul, v. 24, n. 2, p. 209-232, maio 2019. ISSN 1982-6745. Disponível em: https://doi.org/10.17058/redes.v24i2.11655. 